\title{
Penentuan Kedalaman Batuan Dasar Menggunakan Microtremor Array Di Tapak RDE Serpong
}

\author{
Hadi Suntoko*, Sriyana \\ Pusat Kajian Sistem Energi Nuklir - BATAN \\ Jln. Kuningan Barat Mampang Prapatan, Jakarta 12710
}

\begin{tabular}{l}
\hline INFORMASI ARTIKEL \\
\hline Riwayat Artikel: \\
Diterima: \\
17 Februari 2017 \\
Diterima dalam bentuk revisi: \\
22 Februari 2017 \\
Disetujui: \\
1 Maret 2017 \\
\end{tabular}

Kata kunci:

Batuan dasar,

Microtremor array,

Kecepatan gelombang geser, Tapak RDE.

\begin{abstract}
ABSTRAK
PENENTUAN KEDALAMAN BATUAN DASAR MENGGUNAKAN MICROTREMOR ARRAY DI TAPAK RDE SERPONG. Kawasan PUSPIPTEK Serpong merupakan kawasan teknologi tinggi sesuai Rencana Tata Ruang Wilayah (RTRW) Kota Tangerang Selatan, 2011-2031, sehingga kawasan ini ditetapkan sebagai tapak Reaktor Daya Eksperimental (RDE). Untuk menjamin keselamatan, evaluasi tapak dari berbagai aspek harus dilakukan, salah satunya adalah aspek kegempaan. Merujuk Perka BAPETEN Nomor 8 tahun 2013, evaluasi tapak perlu mengkaji kondisi geologi bawah permukaan. Tujuan dari penelitian ini adalah untuk mendapatkan informasi kondisi geologi bawah permukaan khususnya kedalaman batuan dasar di area tapak RDE. Metode yang digunakan dalam penelitian ini adalah microtremor array (MA). Hasil yang diperoleh menunjukkan bahwa tapak RDE memiliki batuan dasar berupa batuan dari Formasi Bojongmanik pada kedalaman 391 meter dari permukaan tanah.
\end{abstract}

\begin{abstract}
DETERMINATION OF BEDROCK DEPTH BY USING MICROTREMOR ARRAYSURVEY AT THE RDE SITE SERPONG. Based on the Strategic Spatial Planning (RTRW) of Tangerang Selatan 2011-2031, PUSPIPTEK Serpong has been appointed as high technology zone, therefore this area is selected as the site for Experimental Power Reactor (Reaktor Daya Eksperimental, RDE). In order to assure safety, site evaluation from several aspects have to be performed, one of which is seismological aspect. Refer to BAPETEN Chairman Regulation No. 8 year 2013, site evaluation should cover the assessment of subsurface geological condition of the site. The objective of this study is to acquire information regarding the subsurface geological condition particularly the bedrock depth of the RDE site area. Method used in this study is microtremor array (MA). The result shows that RDE site has a bedrock type of Bojongmanik Formation at a depth of 391 meter from the surface.

Keywords: Bedrock, microtremor array, shear wave velocity, RDE site.
\end{abstract}

(C) 2016 Jurnal Pengembangan Energi Nuklir. All rights reserved

\section{PENDAHULUAN}

Kawasan PUSPIPTEK Serpong merupakan kawasan teknologi tinggi sesuai RTRW Kota Tangerang Selatan, 2011-2031 [1]. Berdasarkan hal tersebut kawasan PUSPIPTEK Serpong ditetapkan sebagai tapak RDE. Untuk menjamin keselamatan, evaluasi tapak dilakukan terhadap berbagai aspek, salah satunya adalah aspek kegempaan. Berdasarkan Peraturan Kepala BAPETEN Nomor 8 tahun 2013 tentang aspek kegempaan [2], kajian mengenai karakteristik dan kedalaman batuan dasar perlu dilakukan dalam lingkup investigasi area tapak.
Data geologi permukaan tapak RDE menunjukkan bahwa batuan pada lokasi tersebut merupakan bagian atas dari produk gunungapi muda Gn. Gede Salak yang belum terkonsolidasi dengan baik. Selain data geologi permukaan, perlu diketahui pula informasi geologi bawah permukaan terutama posisi batuan padat, masif dan kompak sebagai batuan dasar (bedrock). Batuan dasar berperan sebagai tumpuan dari berbagai jenis material lapisan batuan di atasnya. Jenis batuan ini umumnya berupa batuan Metamorf atau batuan Beku. 


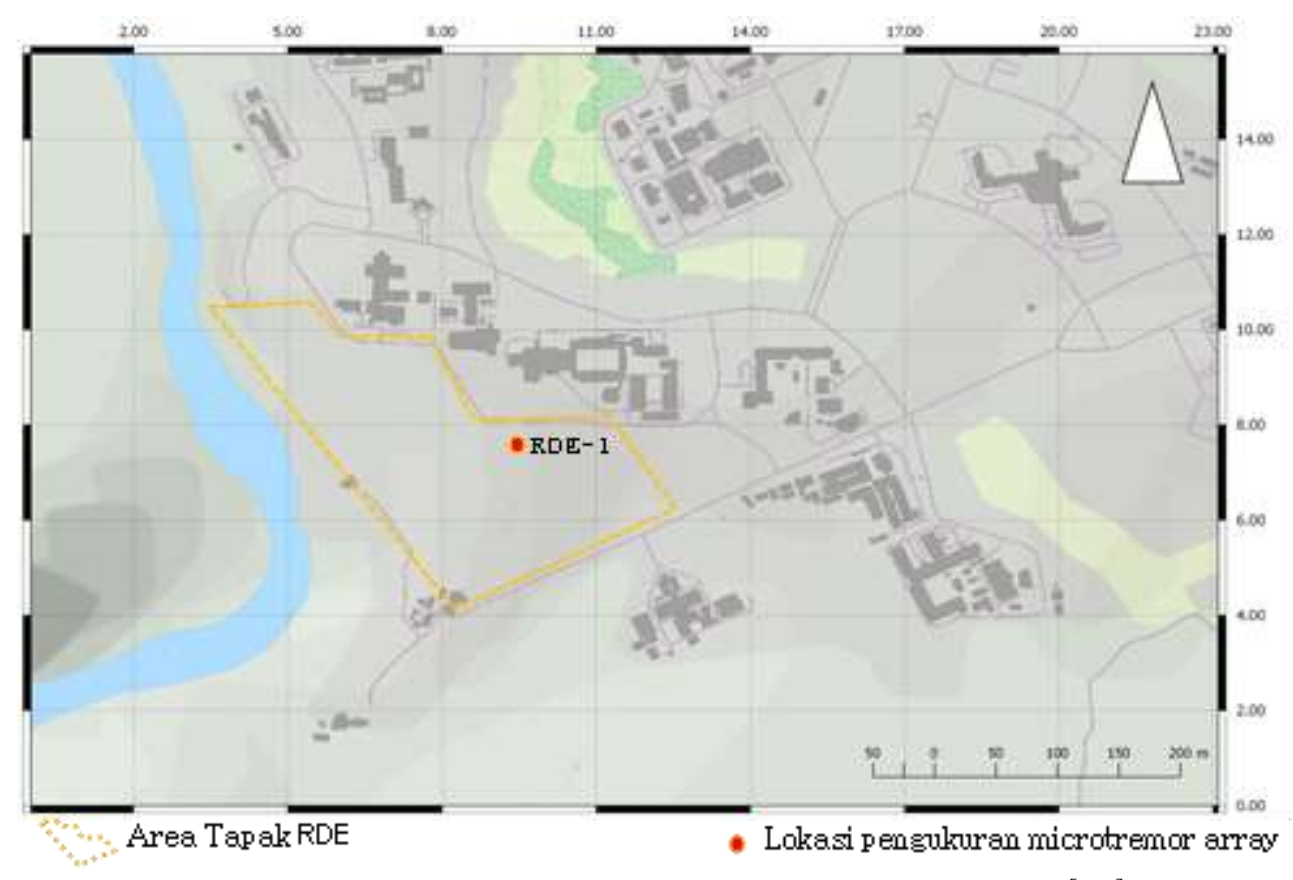

Gambar 1. Peta Lokasi Penelitian di Kawasan Puspiptek, Serpong [14].

Salah satu indikasi keberadaan batuan dasar adalah besarnya nilai kecepatan gelombang geser. Informasi terkait posisi batuan dasar merupakan parameter desain pondasi RDE [3]. Untuk itu diperlukan data seismologi yang dapat memberikan informasi karakteristik batuan dasar dan lapisan tanah/batuan hingga ratusan meter di bawah permukaan [4].

Tujuan dari penelitian ini adalah untuk mendapatkan informasi kondisi geologi bawah permukaan khususnya kedalaman batuan dasar di area tapak RDE. Metode yang digunakan adalah microtremor array. Survei microtremor array (MA) memanfaatkan sifat dispersif gelombang permukaan untuk menduga profil kecepatan rambat gelombang geser terhadap kedalaman.Sensor MA yang digunakan memiliki rentang frekuensi yang lebar dan bervariasi sehingga mempunyai penetrasi gelombang yang lebih dalam. Oleh karena itu, survei MA dapat dimanfaatkan untuk menduga kedalaman batuan dasar yang umumnya berada di kedalaman lebih dari 30 meter [5]. Hasil penelitian ini dapat menjadi masukan bagi penentuan parameter desain RDE.

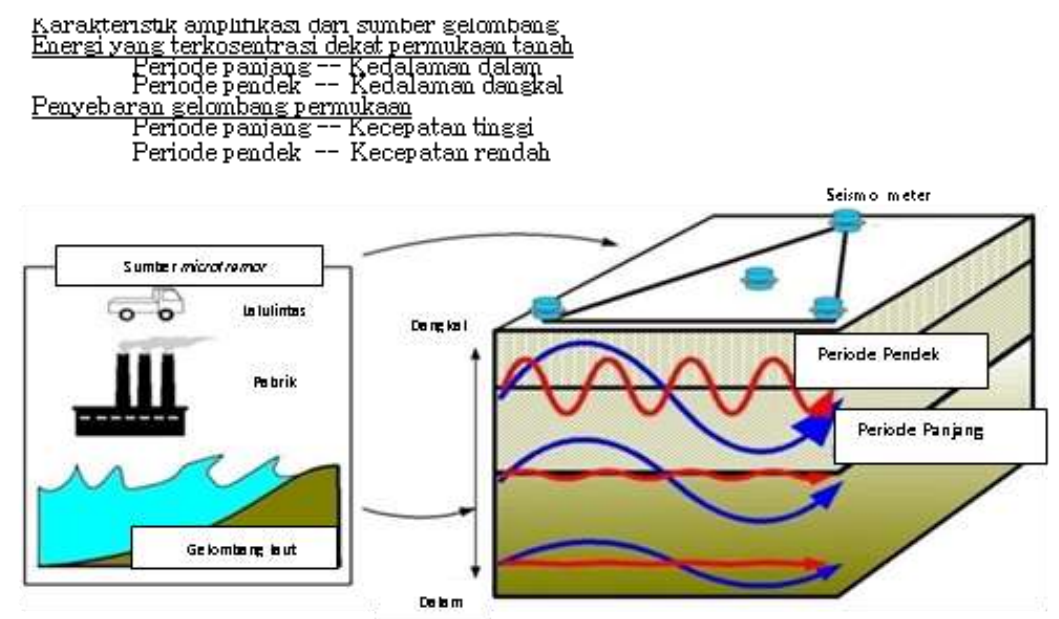

Gambar 2. Survei Microtremor Array dan Sifat Dispersif Gelombang Permukaan dari Sumber Getaran Pasif [8]. 


\section{METODOLOGI}

Lokasi kegiatan berada di kawasan Komplek Puspiptek Serpong, Tangerang Selatan, yaitu di titik RDE-1 (Gambar 1). Konsep dasar survei MA adalah memanfaatkan sumber getaran pasif [6], (Gambar 2). Metode pengambilan data diawali dengan menentukan konfigurasi interval terbesar yang disesuaikan dengan dugaan awal kedalaman batuan dasar (h). Estimasi kedalaman batuan dasar dilakukan berdasarkan data geologi dan justifikasi ahli geologi. Penentuan interval terbesar mengikuti kaidah $h=0,7 \times d$, dengan $d$ adalah jarak antar sensor geofon. Selanjutnya ditentukan konfigurasi interval ke $-2,-3,-4$ dan -5 mengikuti kaidah $d / 2, d / 4$, $d / 8$, dan $d / 16$ berturut-turut[7].

Jika lokasi penempatan sensor tidak kondusif, sensor direlokasi dengan batas toleransi 0.1 kali jarak interval yang bersesuaian. Kemudian sensor diletakkan pada

lokasi yang memungkinkan mendapat sinyal GPS untuk melakukan sinkronisasi waktu antar sensor. Pengukuran dilakukan selama 30 - 60 menit [8]. Pada saat pengukuran getaran yang menganggu dan lalu lalang kegiatan manusia di sekitar area pengukuran harus diminimalkan [9].

Pengumpulan data microtremor array dilakukan menggunakan 4 peralatan unit OYO McSeis 134 (2015) dengan sistem konfigurasi bentuk segitiga[10]. Perekaman data disimpan di logger SARA SL-06 dengan sampling rate $100 \mathrm{~Hz}$. Pengukuran dilakukan pada tiap titik sudut segitiga dengan 5 konfigurasi segitiga (Lihat Gambar 3). Jarak bentang konfigurasi yang digunakan adalah 62.5 meter, 125 meter, 250 meter, 500 meter dan 1000 meter.
Untuk mendapatkan struktur kecepatan gelombang geser vertikal yang sesuai, diperlukan kurva dispersi yang berkualitas dan mencakup rentang frekuensi yang lebar [11]. Pendekatan yang digunakan pada studi ini untuk menghasilkan kurva dispersi yang dibutuhkan adalah dengan metode Spatial Auto Correlation (SPAC). Dalam metode SPAC ini, rekaman getaran gelombang permukaan diperoleh dari konfigurasi (array) sensor yang disusun secara isotropis, misalnya berbentuk segitiga. Tujuannya adalah agar kecepatan dan fase gelombang dari segala arah untuk membentuk kurva dispersi dapat dihitung. Analisis ini sangat efektif untuk pendugaan kecepatan rambat dan informasi profil kecepatan rambat gelombang geser hingga kedalaman batuan dasar lebih dari 30 meter [5].

Metode SPAC didasarkan pada formula Aki (1957) [12] yang merumuskan bahwa bila ada dua stasiun pengamatan mikrotremor berjarak $r$ yang merekam secara simultan maka besarnya nilai koefisien korelasi adalah:

$$
\rho(r, \omega)=J_{0}\left(\frac{\omega}{c(\omega)} r\right)
$$

Dimana; $\omega$ adalah frekuensi anguler; $\mathrm{J}_{0}$ adalah fungsi Bessel jenis pertama orde nol; c( $\omega)$ adalah kecepatan gelombang permukaan.

Berdasarkan Pers. 1, kecepatan gelombang permukaan c $(\omega)$ bersifat dispersif (fungsi frekuensi). Bila fungsi $\rho(r, \omega)$ sudah diketahui maka besarnya kecepatan c dapat diinversi dari kurva dispersinya. Hasil dari inversi berupa struktur kecepatan gelombang geser satu dimensi (1D)[12]. Klasifikasi siteclass didasarkan dari nilai kecepatan gelombang geser (Tabel 1)
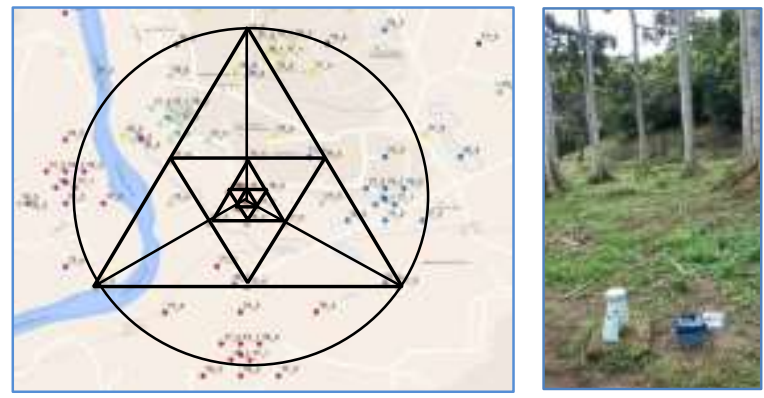

Gambar 3. Pengukuran MA di Titik RDE-1 dengan 5 Konfigurasi [5]. 
Tabel 1. Klasifikasi Tanah Permukaan Berdasarkan pada SNI 1726-2012 [5]

\begin{tabular}{lccc}
\hline Klasifikasi Site & Vs $(\mathrm{m} / \mathrm{d})$ & $\mathrm{N}$ & $\mathrm{Su}(\mathrm{kPa})$ \\
\hline A. Batuan Keras & $\mathrm{Vs} \geq 1500$ & $\mathrm{~N} / \mathrm{A} / \mathrm{A}$ \\
B. Batuan & $750<\mathrm{Vs} \geq 1500$ & $\mathrm{~N} / \mathrm{A}$ & $\mathrm{N} / \mathrm{A}$ \\
C. Tanah sangat & $350<\mathrm{Vs} \leq 750$ & $\mathrm{~N}>50$ & $\mathrm{Su} \geq 100$ \\
$\quad$ padat dan Batuan & & $15 \leq \mathrm{N} \leq 50$ & $50 \leq \mathrm{N} \leq 100$ \\
$\quad$ lunak & $175<\mathrm{Vs} \leq 350$ & $\mathrm{~N}<15$ & $\mathrm{Su}<15$ \\
D. Tanah Sedang & Vs $<175$ &
\end{tabular}

\section{HASIL DAN PEMBAHASAN}

\subsection{Geologi Daerah Penelitian}

Berdasarkan hasil konfirmasi survei geologi terhadap singkapan batuan didapatkan berbagai jenis batuan penyusun daerah Serpong [13]. Di sepanjang aliran Sungai Cisadane dan sungai kecil di sekitarnya ditemukan jenis batuan berupa lempung, lanau, pasir, kerikil, kerakal dan bongkah.

Hampir sebagian besar wilayah penelitian (radius sampai dengan $5 \mathrm{~km}$ ) didominasi oleh batuan penyusun Kipas Aluvial (Qav) yang merupakan material hasil pengendapan dari material vulkanik yang sebelumnya ada dan terendapkan kembali (rework) secara mengalir mulai dari arah selatan ke utara mengikuti landaian topografinya.

Batuan Gunungapi Muda (Qv) tersebar di bagian tengah, baratdaya dan selatan wilayah penelitian dimana paling luas penyebarannya di bagian baratdaya. Di sebelah utara berbatasan dengan Andesit Gunung Sudamanik (Qvas), di sebelah barat dan timur berbatasan dengan Formasi Bojongmanik, dan di sebelah selatan berbatasan dengan Kipas Aluvial (Qav). Qv disusun oleh breksi vulkanik, abuabu kehitaman, dominan matriks, komponen kerakal-bongkah, monomik, terdiri atas basalt, pemilahan buruk, porositas sedang dan tuff, putih kekuningan-kemerahan, halus, dan kekerasan sedang.

Formasi Serpong disusun oleh perselingan tuff kasar dengan konglomerat batuapung, putih terang, terbuka, sortasi baik, dominan matriks, fragmen batuapung berukuran 2-5 cm, matriks tuff kasar, perselingan dengan tuff kasar, kontak berangsur, memiliki arah jurus dan kemiringan perlapisan N 130 E/7. Daerah penyebaran satuan batuan batupasir tufaan berada di sebelah timur sungai Cisadane, dan beberapa tempat kontak langsung dengan satuan batupasir gamping Formasi Bojongmanik [14]. Salah satu singkapannya ditunjukkan pada Gambar 4.

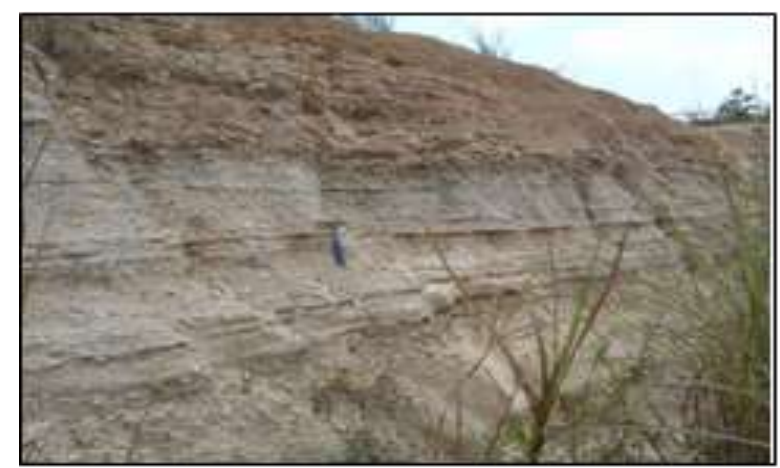

Gambar 4. Singkapan Konglomerat Batuapung Formasi Serpong (Tpss) [14].

Formasi Genteng menempati wilayah yang relatif tinggi dan belum tererosi secara intensif dan menempati daerah sebelah barat Sungai Cisadane, batuan penyusun Formasi Genteng didominasi oleh batuan hasil produk vulkanik dan lapukannya sangat khas berwarna merah sampai merah kecoklatan. Formasi Genteng ini disusun oleh tuff, coklat tua, tuff halus, tuff kasar dan lapilli, berlapis horisontal, antara yang kasar dan halus, scoria dan batuapung, pelapukan sedang sampai tinggi seperti ditunjukkan pada Gambar 5[14].

Formasi Bojongmanik disusun oleh

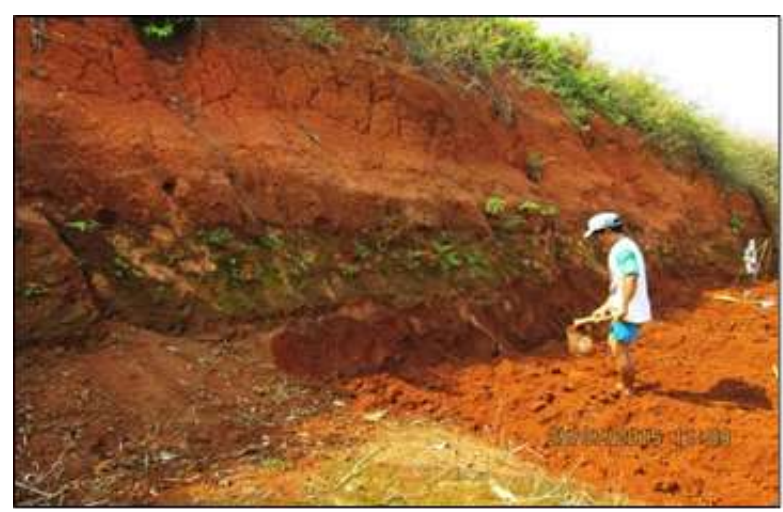

Gambar 5. Singkapan Tuf Batuapung, Formasi Genteng (Tpg) [13]. 
perselingan batupasir, batulempung dan batugamping. Batugamping, abu-abu putih,terang, sangat keras, kristalin, perselingan dengan batugamping pasiran, terdapat sisipan batupasir, abu-abu gelap, karbonan, pasir sedang sampai kasar, memiliki ketebalan sekitar $20 \mathrm{~cm}$, memiliki arah jurus dan kemiringan perlapisan N 35 E/20 dan dibeberapa tempat terdapat lapisan tipis karbonan atau lignit seperti ditunjukkan pada Gambar 6.

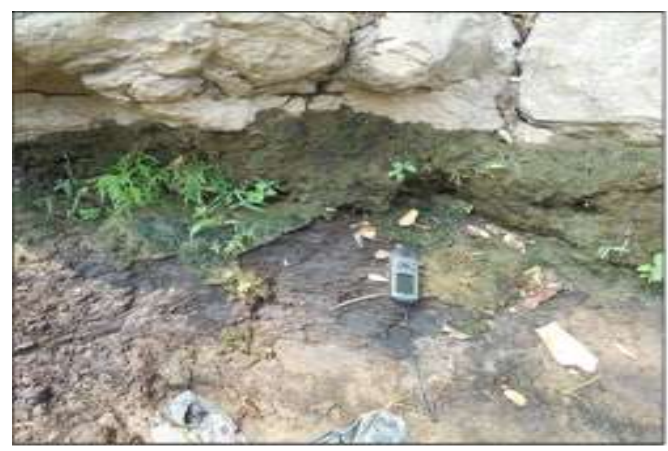

Gambar 6. Singkapan Batupasir Gampingan, Formasi Bojongmanik (Tmb) [13].

\subsection{Pengolahan}

Ploting terhadap kurva hasil analisa metode SPAC didapatkan kurva dispersi (Phase Velocity $(\mathrm{m} / \mathrm{s})$ terhadap Frekuensi $(\mathrm{Hz})$ ) untuk setiap konfigurasi nilai $62.5 \mathrm{~m}$, $125 \mathrm{~m}, 250 \mathrm{~m}, 500 \mathrm{~m}$ sampai $1000 \mathrm{~m}$. Pada titik terdangkal (62.5 meter) menunjukkan kecepatan rendah dengan frekuensi tinggi artinya material tersusun dari bahan lepas, tidak kompak dan umumnya berupa sedimen hasil pelapukan batuan asal. Untuk titik terdalam (1000 meter) menunjukkan kecepatan gelombang hingga $1800 \mathrm{~m} / \mathrm{s}$ dan frekuensi rendah, artinya material penyusun pelapisan merupakan batuan keras, kompak, padat dan kuat (Gambar 7).

Berdasarkan klasifikasi tanah permukaan sesuai standar SNI 1726-2012 pada Tabel 1, bahwa batuan yang memiliki nilai $\mathrm{Vs}=750 \mathrm{~m} / \mathrm{s}$ diklasifikasikan sebagai batuan (batuan dasar) yang masif, keras, kompak dan padat. Oleh karena itu, titik kedalaman 391 m ditetapkan sebagai kedalaman batuan dasar (Tabel 2). Kecepatan gelombang geser memperlihatkan nilai yang confident pada kedalaman $>400 \mathrm{~m}$, sehingga menegaskan bahwa target kecepatan gelombang geser Vs $750 \mathrm{~m} / \mathrm{s}$ terpenuhi (Gambar 8).

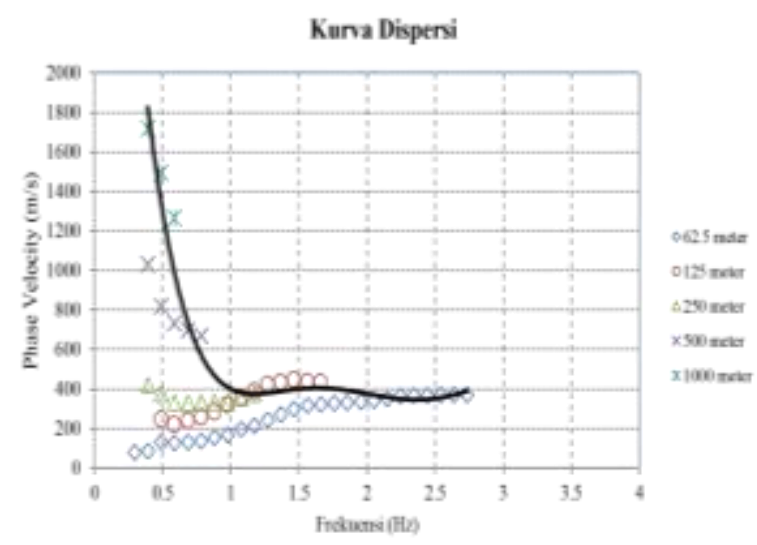

Gambar 7. K urva Dispersi di Titik RDE-1 [13]

Secara umum menunjukkan bahwa struktur kecepatan gelombang pada media tanah hingga kedalaman 391 meter bervariasi terhadap kedalaman [15]. Hal ini disebabkan oleh karakterisasi dari perbedaan respon terhadap gelombang geser akibat heterogenitas batuan penyusun pada lapisan tersebut.

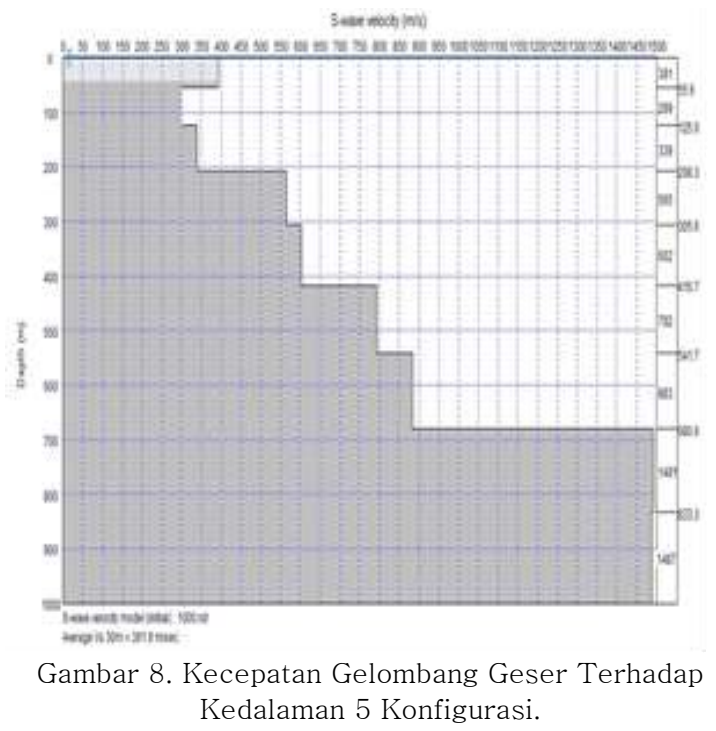

Korelasi hasil konfirmasi geologi dan analisis data gelombang permukaan di tapak RDE-1 menunjukkan bahwa Formasi paling tua dari susunan pelapisan di tapak RDE adalah Formasi Bojongmanik yang memiliki kondisi batuan relatif keras tersusun atas perselingan batupasir, batulempung dan batugamping, abuabu putih, terang, sangat keras, dan sebagian kristalin. Oleh karena itu dapat disimpulkan bahwa batuan dasar pada titik RDE-1 berupa batuan dari Formasi Bojongmanik. 
Tabel 2. Hasil Pengolahan Data Microtremor Array Di Titik RDE-1, Kedalaman Batuan Dasar Pada Permukaan Tanah Dan Terhadap Mean Sea Level (MSL) [5].

\begin{tabular}{|c|c|c|c|c|}
\hline Lokasi & Latitude & Longitude & $\begin{array}{l}\text { Kedalaman Batuan Dasar } \\
\text { (VS } 750 \mathrm{~m} / \mathrm{s} \text { ) pada permukaan tanah }\end{array}$ & $\begin{array}{l}\text { Kedalaman Batuan Dasar } \\
\text { (Vs } 750 \mathrm{~m} / \mathrm{s} \text { ) terhadap MSL }\end{array}$ \\
\hline RDE 1 & -6.3571 & 106.6598 & + 391 meter & +339 meter \\
\hline
\end{tabular}

\section{KESIMPULAN}

Kedalaman batuan dasar diperoleh berdasarkan microtremor array hasil analisis gelombang permukaan/noise menjadi kecepatan gelombang geser (Vs). Nilai kecepatan gelombang geser di tapak RDE-1 menunjukkan nilai $\mathrm{Vs}>750 \mathrm{~m} /$ detik berada pada kedalaman 391 meter yang berupa batuan dari Formasi Bojongmanik.

\section{UCAPAN TERIMA KASIH}

Terima kasih kami sampaikan kepada Kepala Pusat Kajian Sistem Energi Nuklir, Badan Meteorologi Klimatologi Geofisika, Kepala Bidang Kajian Data Tapak dan rekanrekan yang telah membantu, sehingga selesainya laporan ini.

\section{DAFTAR ACUAN}

[1]. Peraturan Daerah Kota Tangerang Selatan No 15 Tahun 2011 tentang Rencana Tata Ruang Wilyah (RTRW) Kota Tengerang Selatan Tahun 20112031. Tangerang Selatan. 2011

[2]. Peraturan Kepala Badan Pengawas Tenaga Nuklir No.8/2013 tentang Evaluasi Tapak Aspek Kegempaan untuk Industri Nuklir. Jakarta. 2013.

[3]. H. Suntoko, M. Nurdin, Y. S. Budi Susilo,I. Hamzah. "Pendeteksian Keberadaan Struktur Sesar pada Batuan Vulkanik dengan Metode Magnetik". Jurnal Eksplorium, Buletin Pusat Teknologi Bahan Galian Nuklir. Vol 33, No 2, November 2012, Hal. 111120.
[4]. "International Training Course: Seismology Seismic Data Analysis Hazard assessment and Risk Mitigation”. GFZ, Postdam, September 2011.

[5]. Marjiyono, et al. "Kelas Sosil Daerah Sekitar Rencana Tapak Reaktor Daya Eksperimental (RDE) Serpong Dari Data Mikrotremor". Jurnal Pengembangan Energi Nuklir. Vol. 17, No.1, Juni 2015, Hal. 57-66.

[6]. Badan Meteorologi Klimatologi dan Geofisika (BMKG). "Laporan Mikrozonasi Getaran Tanah". Jakarta. Desember 2014.

[7]. H. Suntoko, Supartoyo. "Konfirmasi Patahan Permukaan Awal Berdasarkan Data Geologi dan Data Gempa Daerah Kawasan Puspiptek Serpong”. Jurnal Pengembangan Energi Nuklir. Vol. 18, No 1, Juni 2016, Hal. 1-10.

[8]. K. Aki, K. and P. G. Richards. "Quantitative Seismology”. 2nd Edition. University Science Books, New York, USA, 2002.

[9]. Badan Meteorologi Klimatologi dan Geofisika. "Wave (MASW)". Diklat Seismologi Teknik Tahun 2012. Sukabumi, 2012.

[10]. Oyo."Operational Manual and Technical Document: McSEIS-SxW 24 bit XP”. Japan. 2008.

[11]. B. Setiawan, et al. "Analysis of microtremor array measurement using the spatial autocorrelation (SPAC) method across the Adelaide City". School of Civil, Environmental, and Mining Engineering The University of Adelaide. Research Report. No. R 196, November 2016, Pg.3.

[12]. K. Aki. "Space and time spectra of stationary stochastic waves, with special reference to microtremors". Bull. Earthquake Res. Inst. 35, 1957, Pg. 415-456.

[13]. Badan Tenaga Nuklir Nasional (BATAN), "Laporan Evaluasi Tapak Reaktor Daya Eksperimental Kawasan Puspitek Serpong”. Jakarta. Desember 2012.

[14]. T. Turkandi, et al. "Peta Geologi Lembar Jakarta dan Kepulauan Seribu, Jawa”. P3G Badan Geologi, Bandung. 1992.

[15]. I. M., Idriss."Response of Soft Soil Sites During Earthquake”. Proceeding of $H$. Bolton Seed Memorial Symposium. Vol. 2, BiTechPublishers Ltd., Richmond, 1990, pp. 273-289. 